\title{
BMJ Open Investigating admitted patients' satisfaction with nursing care at Debre Berhan Referral Hospital in Ethiopia: a cross-sectional study
}

\author{
Nigussie Tadesse Sharew, ${ }^{1}$ Hailegiorgis Teklegiorgis Bizuneh, ${ }^{1,2}$ \\ Hilina Ketema Assefa, ${ }^{1}$ Tesfa Dejenie Habtewold ${ }^{1,3}$
}

To cite: Sharew NT, Bizuneh HT, Assefa HK, et al. Investigating admitted patients' satisfaction with nursing care at Debre Berhan Referral Hospital in Ethiopia: a crosssectional study. BMJ Open 2018;8:e21107. doi:10.1136/ bmjopen-2017-021107

\section{- Prepublication history for} this paper is available online. To view these files, please visit the journal online (http://dx.doi. org/10.1136/bmjopen-2017021107).

NTS and HTB contributed equally.

Received 12 December 2017 Revised 23 April 2018 Accepted 27 April 2018
Check for updates

${ }^{1}$ Department of Nursing, Debre Berhan University, Debre Berhan, Ethiopia

${ }^{2}$ CJW Medical Center, Richmond, Virginia, USA

${ }^{3}$ Department of Epidemiology and Psychiatry, University of

Groningen, University Medical Center Groningen, Groningen, The Netherlands

Correspondence to Tesfa Dejenie Habtewold; tesfadej2003@gmail.com

\section{ABSTRACT}

Objectives The aims of the study were (1) to assess the level of patient satisfaction with nursing care and (2) to identify factors influencing patient satisfaction.

Design A hospital-based, cross-sectional study was conducted with 252 admitted patients in the medical, surgical and paediatric wards.

Setting Debre Berhan Referral Hospital, Debre Berhan, Ethiopia, with a catchment population of 2.8 million. Participants All patients admitted at least for 2 days and capable of independent communication were included. However, patients were excluded on any one of the following conditions: admitted for less than 2 days, cannot understand Amharic language, with critical illness or cognitive impairment that affects judgement, or inability to provide written informed consent. The mean age of the patients was $37.9(\mathrm{SD}=12.9)$ years, and half $(50.4 \%)$ of them were male.

Primary outcome measure Patient satisfaction with nursing care, measured by the Newcastle Satisfaction with Nursing Scale, was the outcome variable. Using a mean split approach, patient satisfaction scores were dichotomised into 'satisfied' and 'unsatisfied'.

Results $49.2 \%$ of patients were satisfied with nursing care. Educational status and history of admission were significant factors influencing patient satisfaction with nursing care. Patients who had high educational status were $80 \%$ less satisfied compared with those who had no formal education ( $p=0.01,0 R=0.2,95 \% \mathrm{Cl} 0.1$ to 0.7 ). Patients who had a history of admission were 2.2 times more satisfied compared with those who had no history of admission ( $p=0.02,0 \mathrm{R}=2.2,95 \% \mathrm{Cl} 1.2$ to 4.2 ).

Conclusions About half the admitted patients were satisfied with the nursing care. Satisfaction differed significantly by patients' educational attainment and history of admission. This study provided evidence on patient satisfaction with nursing care in Ethiopia. This information may be useful in comparative studies of patient satisfaction and in identifying characteristics that may explain or predict patient satisfaction.

\section{BACKGROUND}

Satisfaction is a belief and an expression of attitude about a particular service process. ${ }^{1}$ It has three major components: emotional
Strengths and limitations of this study

- The study used a standardised patient satisfaction scale.

- The study has a reasonably large sample size.

- The patient satisfaction scale has not been validated in an Ethiopian context.

- There is social desirability bias because patients may feel hesitant to provide feedback that may negatively affect their relationship with hospital staff.

- Potentially relevant variables such as medical diagnosis, severity and duration of illness, and medication history were not included.

or cognitive response; expectations, product and consumption experience; and experience-based response after consumption and choice. ${ }^{2}$ Patient satisfaction is defined as the patient's subjective evaluation of his/her cognitive and emotional reaction as a result of the interaction between expectations and perception of actual care. ${ }^{3}$ Patient satisfaction has become an established outcome indicator, a tool to analyse the quality of a healthcare system, ${ }^{4}$ and input to develop strategies for accessible, sustainable, affordable and acceptable patient care. ${ }^{1}$

Risser's ${ }^{5}$ first proposed definition of patient satisfaction is the degree of congruence between a patient's expectation of ideal nursing care and their perception of the actual nursing care received. The American Nurses Association's definition of patient satisfaction with nursing, the patient's opinion of care received from nurses during their hospitalisation, is adapted for our study. ${ }^{6}$ Patient satisfaction with nursing care has the following components: expectation, hospital physical environment, communication and information, participation and involvement, interpersonal relations, and competence. ${ }^{7}$ Since nurses spend most of their time with patients, 
they have a great role in determining overall patient satisfaction. ${ }^{8}$ In addition, nurses provide up to $80 \%$ of primary healthcare. ${ }^{10}$ Thus, dissatisfaction with the nursing care may indicate poor healthcare quality and decreases the achievement of standards. ${ }^{411}$

A review of literature shows variability in the per cent of patients reporting satisfaction with nursing care: $73 \%$ in India, ${ }^{12} 51.7 \%$ in Serbia, ${ }^{13} 57.8 \%$ in the Philippines, ${ }^{8}$ $54.8 \%$ in Turkey ${ }^{14}$ and $82.7 \%$ in Malaysia. ${ }^{15}$ In Ethiopia, patient satisfaction with nursing care is $67 \%$ at Black Lion Hospital, ${ }^{16} 81.8 \%$ at Felege Hiwot Referral Hospital and Finote Selam Hospital, ${ }^{17}$ and $56.9 \%$ at Debre Markos Hospital. ${ }^{18}$ Factors influencing patients' satisfaction with nursing care are age, gender, educational status and the healthcare system. ${ }^{7}$ A study conducted in South Africa and China also reveals an association between patients' satisfaction with nursing care and occupation, methods of payment, admission ward and severity of illness. ${ }^{19} 20$ Furthermore, monthly family income, ${ }^{21}$ nature of care provided, ${ }^{22-24}$ maintaining dignity and privacy, ${ }^{25}{ }^{26}$ and emotional support and empathy ${ }^{27}$ were significant factors influencing patient satisfaction with nursing care. On the contrary, recent studies depict the absence of a significant association between patient satisfaction with nursing care and patients' sociodemographic characteristics (age, gender, educational status), nursing competence, skill mix, clinical experience, nurse to patient ratio and number of beds. ${ }^{28-31}$

Patient satisfaction is low in Sub-Saharan Africa due to the following reasons: inadequate nurse to population ratio, inadequate competency, scarcity of resources and ineffective healthcare system. ${ }^{32}{ }^{33}$ The World Bank study group in Ethiopia reported that the ratio of healthcare workers to the population is 0.84 per 1000 population. Even though Ethiopia has the highest number of healthcare workers in Sub-Saharan Africa (65 554), the ratio of healthcare workers to the population is below the WHO standard of 2.28 per 1000 population. ${ }^{34}$ The total number of nurses in Ethiopia is 20109 (0.26 nurse per 1000 population), with nurses representing the second largest group of healthcare workers. ${ }^{33}$ Despite the greatest inadequacy for physicians (1 per 42706 population), the number of other health professionals, such as health officers, nurses, midwives and health extension workers, has shown a dramatic improvement over the past 5 years. Ethiopia has also achieved the minimum WHO recommendation of 1 nurse per 5000 population. ${ }^{35}$ Currently, the Ethiopian government has been implementing the nursing process and training nurses in different specialties (eg, medical nursing, surgical nursing, neonatal nursing, emergency nursing, family nursing). In Ethiopia, nursing education has made a substantial progress; the Ministry of Health and the Ministry of Education proposed the baccalaureate degree as the minimum educational requirement for professional nursing practitioners. Nurses can also earn master's degrees and doctoral degrees $(\mathrm{PhD})$ in national or international universities. Nurses in Ethiopia engage in a variety of tasks, including nursing care, teaching, research and management. ${ }^{36}$

Reviewed literature shows that evidence on the level of patient satisfaction with nursing care and factors influencing satisfaction is mixed across countries. ${ }^{3}{ }^{37-39}$ The possible explanations for the differences could be variations in sample size, the operationalisation of patient satisfaction, methodological variation (eg, use of culturally validated satisfaction scales), and the difference in cultural beliefs and values. Thus, country-specific data are still required to provide evidence for cross-country and cross-cultural comparisons in satisfaction level and factors affecting satisfaction using a standardised tool. ${ }^{32}$ To our knowledge, this is the first study at Debre Berhan Referral Hospital (DBRH). This study has two aims: (1) to assess the level of patient satisfaction with nursing care and (2) to examine the influence of factors affecting patient satisfaction with nursing care.

\section{METHODS AND MATERIALS \\ Study setting}

Debre Berhan is located $130 \mathrm{~km}$ north-east of Addis Ababa, which is the capital city of Ethiopia. It has nine kebeles (the smallest administrative unit in Ethiopia) with a total population of 94829 individuals, $50.8 \%$ of whom are female. In Debre Berhan, two hospitals, three health centres and seventeen private clinics provide healthcare services. ${ }^{40}$ This study was conducted at DBRH, a 150-bed facility with a catchment population of 2.8 million people. ${ }^{41}$ The services at DBRH include ear, nose and throat, surgery, outpatients department, emergency, tuberculosis and HIV, gynaecology and obstetrics, paediatrics and neonatal intensive care unit (NICU), maternal and child health, physiotherapy, dental, radiology, psychiatry, and internal medicine. Even though DBRH is not affiliated with any of the teaching colleges or universities, it is a teaching hospital for nursing, health officer, medicine, midwifery and pharmacy undergraduate and graduate students. The hospital has a total of 334 healthcare employees: 38 physicians, 180 nurses, 26 midwives, 7 anaesthetists, 31 laboratory technicians, 2 physiotherapists, 4 dentists, 6 radiographers, 4 optometrists and 36 pharmacists. ${ }^{42}$ The types of nurses in DBRH are NICU nurses, surgical nurses, paediatrics nurses, operation room nurses, emergency nurses and psychiatry nurses. The hospital has implemented nursing process since 2010.

\section{Patient and public involvement}

The research question and outcome measures were developed by the authors (NTS and HKA) in consultation with ward nurses who understand patients' priorities, experiences and preferences. Patients were involved in the design of this study via their advisers (ward nurses) and were directly recruited and interviewed by the authors to evaluate their level of satisfaction with nursing care. The results of this study will be disseminated to patients by 
means of health education and by relaying the key findings in Amharic, the local language.

\section{Study design and sampling}

This hospital-based, cross-sectional study was conducted with 252 admitted patients between April and May of 2015. All patients admitted in the selected wards at least for 2 days and capable of independent communication were included. However, patients were excluded on any one of the following conditions: admitted for less than 2 days, cannot understand Amharic language, with critical illness or cognitive impairment that affects judgement, or inability to provide written informed consent. The required sample size was determined using a single population proportion formula using the following assumptions: $95 \%$ confidence level, $5 \%$ level of statistical significance, $81.8 \%$ patient satisfaction with nursing care $^{17}$ and $10 \%$ non-response rate. First, considering the number of patients admitted and the implementation of the nursing process, medical, surgical and paediatric wards were purposefully selected. Second, based on the calculated sample size, the required number of patients from each ward was proportionally allocated. Finally, a quota random sampling method was used to select an individual patient.

\section{Measurements and instruments}

The questionnaire included sociodemographic characteristics (eg, age, sex, religion, occupational status, educational status, marital status and monthly family income), history of admission (eg, having been admitted previously to DBRH for the same or different condition), hospital length of stay, admission ward, satisfaction with overall ward services and the Newcastle Satisfaction with Nursing Scale (NSNS) to measure satisfaction with nursing care. The American Nurses Association's definition was used to conceptualise patient satisfaction with nursing care. ${ }^{6}$ Satisfaction with overall ward services was assessed using a single item: 'How would you rate your satisfaction with the overall service given in this ward?' Trained nursing student interns approached patients during their hospital stay for recruitment. Written informed consent was obtained after explaining the objectives of the study. Five trained nursing student interns administered the questionnaire in Amharic, the local language; translation into the local language was done in consultation with professionals fluent in English and Amharic. In the paediatric ward, parents or guardians were interviewed. A private room at the hospital was used to interview patients, as it was believed to provide privacy and aid in the attainment of honest responses from the participants. Family members were present during some of the interviews at the request of some patients. In addition, medical records were reviewed for certain variables such as hospital length of stay and history of admission. The NSNS comprised two subscales: experiences of nursing care and satisfaction of care. In the current study, only the satisfaction of care subscale ${ }^{43}$ was used because of feasibility issue. The satisfaction subscale assesses satisfaction with all aspects of nursing care using 19 items rated on a 5-point Likert scale (not at all satisfied, barely satisfied, quite satisfied, very satisfied, completely satisfied). The NSNS tool had an excellent reliability (Cronbach's $\alpha=0.96$ ) and construct validity. ${ }^{43}$ In our study, the NSNS tool had an excellent reliability with a Cronbach's $\alpha$ of 0.98 and intraclass correlation of 0.97 . A satisfaction sum score for each patient and the mean (ie, 63.9) were calculated. The satisfaction score was standardised by dividing the mean value by the number of the NSNS items (ie, 3.36). A mean split approach (ie, using the mean satisfaction score as a cut point) was used to dichotomise satisfaction into 'satisfied' (ie, satisfaction score $\geq 63.9$ ) and 'not satisfied' (ie, satisfaction core $<63.9$ ). We dichotomised the satisfaction score to ease translation into clinical practice. In addition, we believe there are distinct groups of patients as we were interested in group differences rather than individual differences. ${ }^{45}$

\section{Statistical analysis}

The printed frequency was used to check accuracy, consistency and missed values of variables. Bivariate and multiple logistic regression analyses were done to identify factors associated with satisfaction. The strength of the associations was described using ORs and $95 \%$ CI at the 0.05 level of statistical significance. Data were presented using descriptive statement and tables. EPI Info V.3.5.1 statistical software was used for data entry and coding, whereas the Statistical Package for the Social Sciences (SPSS V.20) was used for data analysis. The study was adherent to the Strengthening the Reporting of Observational Studies in Epidemiology statement. ${ }^{46}$

\section{RESULTS}

\section{Baseline characteristics}

A total of 252 admitted patients were interviewed. The patients had a mean age of 37.9 (SD 12.9) years. Half $(50.4 \%)$ of the patients were male, $61.5 \%$ were married, $41.7 \%$ were farmers and $36.9 \%$ were illiterate. The average length of hospital stay was 6.44 days $(\mathrm{SD}=4.46)$. More than three-quarters (79\%) of patients knew a nurse in charge of their nursing care (table 1).

\section{Satisfaction with nursing care}

Of the patients, $49.2 \%$ were satisfied with nursing care. The average patient satisfaction score was $63.9(\mathrm{SD}=17)$. Patients' satisfaction with overall ward service was $64.7 \%$. As presented in table 2, about one out of ten admitted patients was not satisfied with their freedom in their ward $(8.7 \%)$, nurses' willingness to respond to their needs $(8.3 \%)$, privacy $(8.3 \%)$ and information provided by nurses $(7.9 \%)$.

\section{Factors influencing satisfaction}

Educational status and history of admission were significant factors influencing patient satisfaction with nursing 
Table 1 Sociodemographic characteristics and medical history of patients

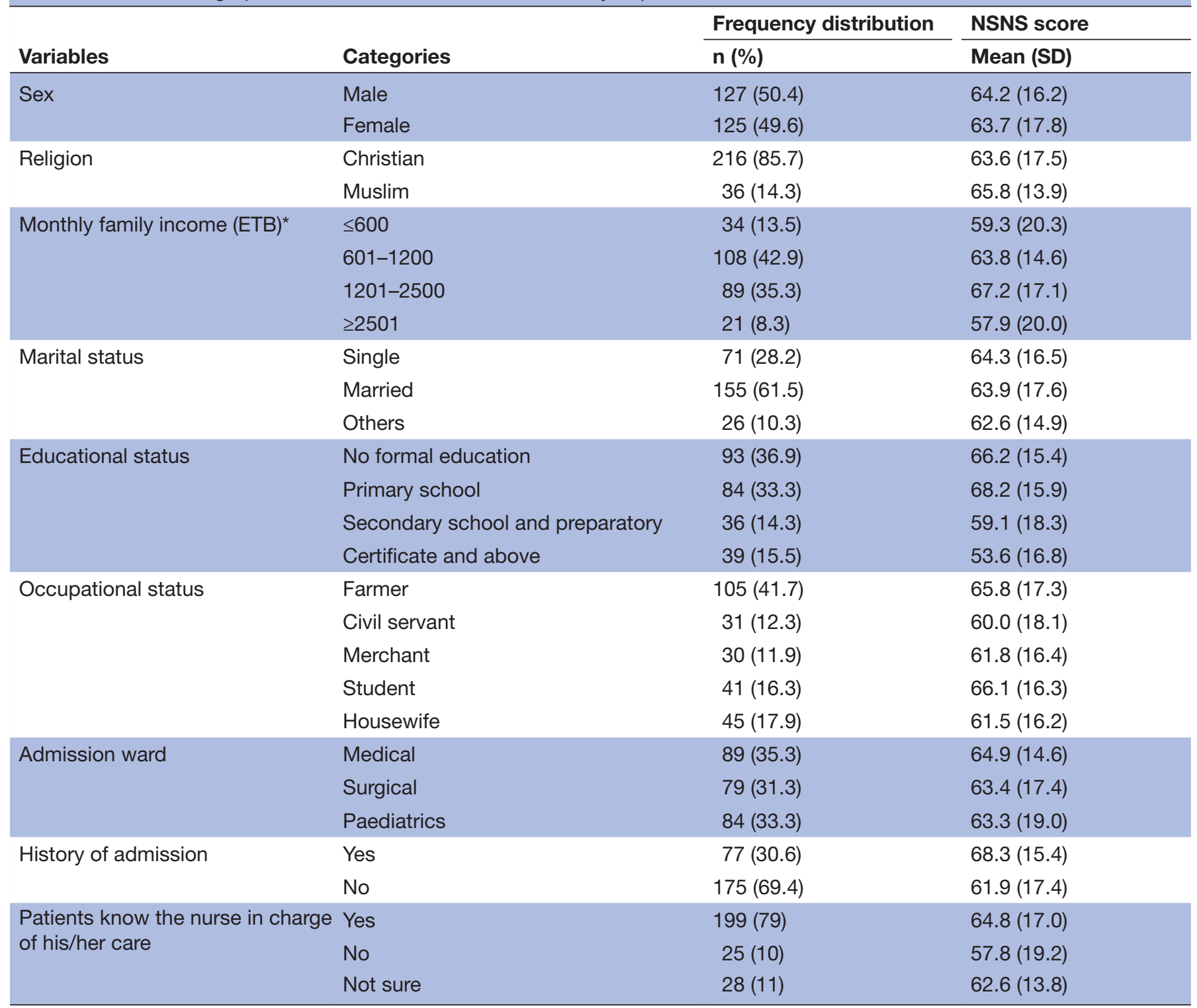

*US\$1 is 27.44 Ethiopian birr (ETB).

NSNS, Newcastle Satisfaction with Nursing Scale.

care. Patients who have higher educational status were $80 \%$ less satisfied compared with those who have no formal education ( $\mathrm{p}=0.01, \mathrm{OR}=0.2,95 \%$ CI 0.1 to 0.7$)$. In addition, patients who had a history of admission were 2.2 times more satisfied compared with those who did not have a history of admission $(\mathrm{p}=0.02, \mathrm{OR}=2.2,95 \%$ CI 1.2 to 4.2) (table 3).

\section{DISCUSSION}

This study investigated the level of patient satisfaction with nursing care and its associated factors. Our study showed that $49.2 \%$ and $64.7 \%$ of admitted patients were satisfied with the nursing care and overall ward service at DBRH, respectively. Educational status and history of admission were significantly associated with patient satisfaction.
The level of patient satisfaction with nursing care in our study $(49.2 \%)$ was lower than previous studies in Serbia $(51.7 \%),{ }^{13}$ the Philippines $(57.8 \%),{ }^{8}$ Turkey $(54.8 \%),{ }^{14}$ India $(73 \%),{ }^{12}$ Iran $(82.8 \%),{ }^{11}$ Malaysia $(82.7 \%)^{6}$ and Ethiopia $(56.9 \%-81.8 \%) .{ }^{16-18}$ This discrepancy in satisfaction level may be due to the difference in the operationalisation of satisfaction and techniques to determine satisfaction status. We strictly defined patients' satisfaction status using the mean score as a cut point. Usually patients admitted to the medical, surgical and paediatric wards are critically ill, which possibly affects their satisfaction. In addition, the use of a different satisfaction scale may also explain variation in satisfaction levels between the current study and previous studies. For example, the studies in Iran $^{11}$ and Malaysia ${ }^{6}$ used the 39-item Patient Satisfaction Questionnaire and Self-Report Nursing Care 
Table 2 Patient satisfaction with nursing care at Debre Berhan Referral Hospital

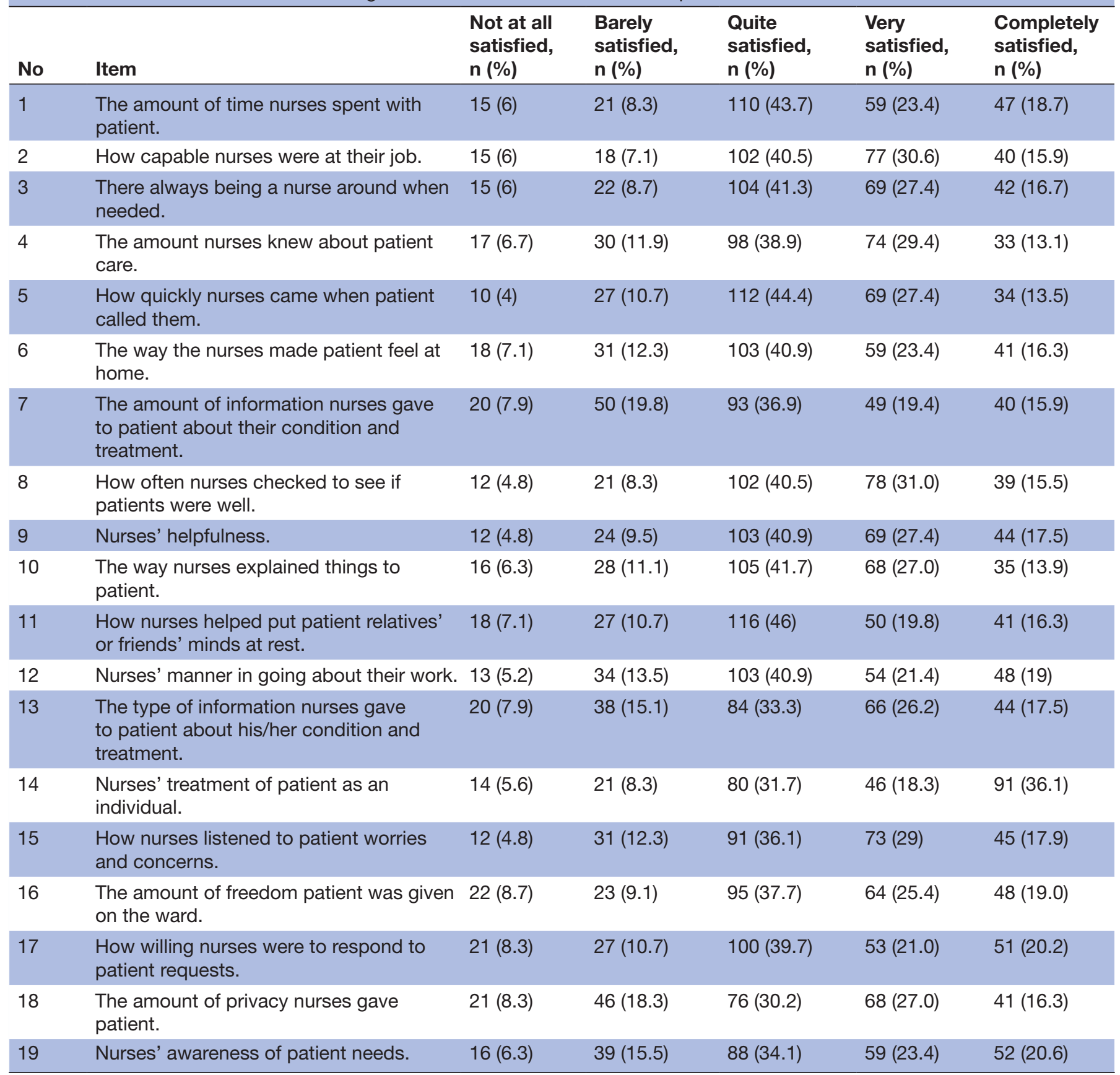

Scale, respectively. Furthermore, the characteristics of the samples, hospitals, types of services offered, skill mix of nurses, and cultural beliefs and values could have contributed to these differences.

In agreement with the previous studies, ${ }^{16} 1747-49$ this study revealed that nearly half of patients were satisfied with the amount of time nurses spent with them $(43.7 \%)$, nurses' quick response $(44.4 \%)$ and nurses' help to their relatives or friends $(46.0 \%)$ compared with other dimensions of satisfaction. However, the study conducted in north-west Ethiopia showed $78.3 \%, 72.4 \%$ and $69.7 \%$ of patients were satisfied with the amount of time nurses spent with them, nurses' quick response and nurses' help to their relatives or friends. ${ }^{17}$ This discrepancy may be due to high patient flow, availability of hospital resources such as bedscreens and the competency of nurses to implement all aspects of nursing care. Since the nurse to patient ratio in the population is small, ${ }^{35}$ the amount of time nurses spent with patients may be less, and the nursing care provided may not be optimal. In addition, high patient flow leads to a shortage of rooms and other resources helpful in providing satisfactory patient care.

In this study, patients who had high educational status were significantly less likely $(80 \%)$ to be satisfied compared with those who had no formal education $(p=0.01)$. This finding is consistent with the study by 
Table 3 Factors influencing patient satisfaction with nursing care

\begin{tabular}{|c|c|c|c|c|c|c|}
\hline \multirow[b]{2}{*}{ Variables } & \multirow[b]{2}{*}{ Categories } & \multicolumn{2}{|l|}{ Satisfaction status } & \multirow[b]{2}{*}{$P$ values } & \multirow[b]{2}{*}{ OR } & \multirow[b]{2}{*}{$95 \% \mathrm{Cl}$} \\
\hline & & $\begin{array}{l}\text { Satisfied } \\
\text { (score } \geq 63.9) \text { n (\%) }\end{array}$ & $\begin{array}{l}\text { Not satisfied } \\
\text { (score <63.9) n (\%) }\end{array}$ & & & \\
\hline \multirow[t]{2}{*}{ Sex } & Male & $60(47.2)$ & $67(52.8)$ & 1 & 1 & \\
\hline & Female & $64(51.2)$ & $61(48.8)$ & 0.48 & 0.8 & 0.4 to 15 \\
\hline \multirow{4}{*}{$\begin{array}{l}\text { Monthly family } \\
\text { income (ETB) }\end{array}$} & $\leq 600$ & $20(58.8)$ & $14(41.2)$ & 1 & 1 & \\
\hline & $601-1200$ & $54(50.0)$ & $54(50.0)$ & 0.53 & 1.3 & 0.6 to 3.1 \\
\hline & $1201-2500$ & $37(41.6)$ & $52(58.4)$ & 0.14 & 1.9 & 0.8 to 4.7 \\
\hline & $\geq 2501$ & $37(41.6)$ & $52(58.4)$ & 0.40 & 0.6 & 0.2 to 2.1 \\
\hline \multirow[t]{4}{*}{ Educational status } & No formal education & $46(49.5)$ & $47(50.5)$ & 1 & 1 & \\
\hline & Primary school & $30(35.7)$ & $54(64.3)$ & 0.10 & 1.8 & 0.9 to 3.7 \\
\hline & $\begin{array}{l}\text { Secondary school } \\
\text { and preparatory }\end{array}$ & $23(63.9)$ & $13(36.1)$ & 0.25 & 0.5 & 0.2 to 1.5 \\
\hline & Certificate and above & $25(64.1)$ & $14(35.9)$ & $0.01^{*}$ & 0.2 & 0.1 to 0.7 \\
\hline \multirow[t]{4}{*}{ Occupational status } & Farmer & $47(44.8)$ & $58(55.2)$ & 1 & 1 & \\
\hline & Civil servant & $15(48.4)$ & $16(51.6)$ & 0.08 & 2.7 & 0.9 to 8.3 \\
\hline & Merchant & $18(60.0)$ & $12(40.0)$ & 0.16 & 0.5 & 0.2 to 1.3 \\
\hline & Student & $18(43.9)$ & $23(56.1)$ & 0.93 & 0.9 & 0.4 to 2.5 \\
\hline History of admission & No & $94(53.7)$ & $81(46.3)$ & 1 & 1 & \\
\hline \multirow{3}{*}{$\begin{array}{l}\text { Patients know the } \\
\text { nurse in charge of } \\
\text { his/her care }\end{array}$} & Yes & $93(46.7)$ & 106 (53.3) & 1 & 1 & \\
\hline & No & $16(64.0)$ & $9(36.0)$ & 0.09 & 0.5 & 0.2 to 1.2 \\
\hline & Not sure & $15(53.6)$ & $13(46.4)$ & 0.34 & 0.6 & 0.3 to 1.6 \\
\hline \multicolumn{4}{|l|}{ Length of stay in ward } & 0.86 & 1.0 & 0.9 to 1.1 \\
\hline
\end{tabular}

ETB, Ethiopian birr.

${ }^{*}$, Statistically significant

Woldeyohanes and colleagues $(\mathrm{p}=0.004),{ }^{50}$ Dzomeku and colleagues $(\mathrm{p}<0.05)^{51}$ and Findik and colleagues $(p=0.03) .^{52}$ The possible explanation was that patients who had high educational status may have a variety of expectations and may also be more aware of the standard levels of nursing care, leaving them less satisfied with the care they received. This hypothesis was supported by a previous study in which expectation highly correlated with patient satisfaction. ${ }^{53}$ In contrary to Ahmed and colleagues' finding $(\mathrm{p}<0.05),{ }^{49}$ we found that patients who had a history of admission were more than twice as likely to be satisfied compared with those who had no history of admission $(\mathrm{p}=0.02)$. This could be related to the previous positive relationship with nurses, good quality of care and affordable service cost that possibly improved their perception of the current nursing care.

This study has several strengths: high response rate, use of a standardised patient satisfaction scale and a reasonably large sample size. However, certain limitations are also acknowledged. Social desirability bias may influence patients' responses, causing them to report more positive experiences so as not to negatively impact their relationships with nurses. Even though a standardised questionnaire was used, it is not validated for use in an Ethiopian 
population. Readers should also interpret the results cautiously because the satisfaction scores were dichotomised, which possibly contributes to loss of specificity and power. The sample size calculation did not consider a number of different factors influencing patient satisfaction. In addition, potentially relevant variables such as medical diagnosis, severity and duration of illness, and medication history were not included. Lastly, this study was conducted in one institution, which might limit the external validity of the results.

This study provides evidence on patient satisfaction with nursing care in an Ethiopian context, which can be useful for researchers conducting comparative research on patient satisfaction and related factors. This study also elucidates important factors that can help clinicians and administrators to predict and improve satisfaction in a hospital setting. To increase satisfaction with nursing care, greater emphasis should be given to patient privacy, freedom and communication. In addition, it is relevant to perform periodical community need assessment to identify individuals' expectations and create awareness of hospital services. Even though hospitals have their own nursing care standards, it is important to provide information to patients regarding nursing care and their related expectations, as it has been shown that expectations are of great importance for increasing satisfaction. ${ }^{25}$ Researchers should also inform hospital administrators and politicians of what the community can expect from care and what demands they can place on it so that this can be made known to the public. ${ }^{7}$ Furthermore, to obtain a better estimate of satisfaction with nursing care, it is important to conduct a large-scale study to assess the experience and satisfaction of nursing care in several hospitals using an exit-interview method.

Acknowledgements The authors' indepth gratitude goes to Debre Berhan University's Institute of Medicine and Health Science for approval of the study protocol. The authors' recognition also extends to Debre Berhan Referral Hospital officials, Sr Tseganesh Biyabil (Matron Nurse), Dr Feseha Tadesse (Medical Director) and patient advisers (ward nurses) who facilitated patient recruitment and data collection. The authors would like to acknowledge Dr Stephanie Grutzmacher (Oregon State University, USA), who copyedited the manuscript, and Mulugeta Molla (Mekelle University, Ethiopia) and Andreas Teferra (University of Groningen, The Netherlands), who provided intellectual comments during manuscript writing. Lastly, the authors' heartfelt gratitude and high appreciation also go to data collectors (Derese Asfaw, Mandye Nigatu, Seble Kifle and Smegn Tubulu) and the patients who participated in this study.

Contributors NTS was involved in supervision during proposal writing, data collection and data entry. HTB was involved in proposal writing, designing the questionnaire, participant selection, data collection and data entry. HKA was involved in supervision during proposal writing, data collection and data entry. TDH was involved in data management, data analysis, and manuscript writing and revision.

Funding This research received no specific grant from any funding agency in the public, commercial or not-for-profit sectors.

Competing interests None declared.

Patient consent Obtained.

Ethics approval In order to conform to the Declaration of Helsinki (1964) and Population Screening Act (WBO), ethical clearance was obtained from Debre Berhan University, Institute of Medicine and Health Science Ethical Review Committee. Additionally, written informed consent was received from each patient.
In the paediatric ward, written informed consent was obtained from parents or guardians.

Provenance and peer review Not commissioned; externally peer reviewed.

Data sharing statement All the data used in this study were included in the main documents.

Open Access This is an Open Access article distributed in accordance with the Creative Commons Attribution Non Commercial (CC BY-NC 4.0) license, which permits others to distribute, remix, adapt, build upon this work non-commercially, and license their derivative works on different terms, provided the original work is properly cited and the use is non-commercial. See: http://creativecommons.org/ licenses/by-nc/4.0/

(C) Article author(s) (or their employer(s) unless otherwise stated in the text of the article) 2018. All rights reserved. No commercial use is permitted unless otherwise expressly granted.

\section{REFERENCES}

1. Penchansky R, Thomas JW. The concept of access: definition and relationship to consumer satisfaction. Med Care 1981;19:127-40.

2. Oliver RL. A conceptual model of service quality and service satisfaction: Compatible goals, different concepts. Advances in services marketing and management 1993;2:65-85.

3. Ozsoy SA, Ozgür G, Durmaz Akyol A. Patient expectation and satisfaction with nursing care in Turkey: a literature review. Int Nurs Rev 2007;54:249-55

4. Merkouris A, Papathanassoglou ED, Lemonidou C. Evaluation of patient satisfaction with nursing care: quantitative or qualitative approach? Int J Nurs Stud 2004;41:355-67.

5. Risser NL. Development of an instrument to measure patient satisfaction with nurses and nursing care in primary care settings. Nurs Res 1975;24:45-51.

6. Teng K, Norazliah S. Surgical patients' satisfaction of nursing care at the orthopedic wards in hospital universiti sains malaysia (HUSM). $J$ Environ Health 2012;3:36-43.

7. Johansson $P$, Oléni $M$, Fridlund $B$. Patient satisfaction with nursing care in the context of health care: a literature study. Scand J Caring Sci 2002;16:337-44.

8. Villarruz-Sulit MVC, Dans AL, Javelosa MAU. Measuring satisfaction with nursing care of patients admitted in the medical wards of the philippine general hospital. Acta Med Philipp 2009;43:52-6.

9. Laschinger HS, Hall LM, Pedersen C, et al. A psychometric analysis of the patient satisfaction with nursing care quality questionnaire: an actionable approach to measuring patient satisfaction. J Nurs Care Qual 2005;20:220-30.

10. Hughes F. Nurses at the forefront of innovation. Int Nurs Rev 2006:53:94-101.

11. Akhtari-Zavare M, Abdullah MY, Abdullah MY, et al. Patient satisfaction: evaluating nursing care for patients hospitalized with cancer in Tehran teaching hospitals, Iran. Glob J Health Sci 2010;2:117.

12. Sharma A, Kasar P, Sharma R. Patient satisfaction about hospita services: a study from the outpatient department of tertiary care hospital, jabalpur, madhya pradesh, india. National J Community Medicine 2014:5:199-203.

13. Milutinović D, Simin D, Brkić N, et al. The patient satisfaction with nursing care quality: the psychometric study of the Serbian version of PSNCQ questionnaire. Scand J Caring Sci 2012;26:598-606.

14. Erci B, Ciftçioglu S. Psychometric evaluation of the primary healthcare satisfaction scale in Turkish women. Int J Qual Health Care 2010;22:500-6

15. Tang WM, Soong C, Lim WC. Patient satisfaction with nursing care: a descriptive study using interaction model of client health behavior. International Journal of Nursing Science 2013;3:51-6.

16. CHAKA B. Adult patient satisfaction with nursing care. 2005.

17. Negash AK. Patients' satisfaction and associated factors with nursing care services in selected hospitals, Northwest Ethiopia. American Journal of Nursing Science 2014;3:34-42.

18. Alemu S. Changes in inpatient satisfaction with nursing care and communication at Debre Markos Hospital, Amhara Region, Ethiopia. American Journal of Health Research 2014;2:171-6.

19. Liu $Y$, Wang $G$. Inpatient satisfaction with nursing care and factors influencing satisfaction in a teaching hospital in China. J Nurs Care Qual 2007;22:266-71.

20. Westaway MS, Rheeder P, Van Zyl DG, et al. Interpersonal and organizational dimensions of patient satisfaction: the moderating effects of health status. Int J Qual Health Care 2003;15:337-44. 
21. Etter JF, Perneger TV. Validating a satisfaction questionnaire using multiple approaches: a case study. Soc Sci Med 1997;45:879-85.

22. Lin HC, Xirasagar S, Laditka JN. Patient perceptions of service quality in group versus solo practice clinics. Int J Qual Health Care 2004;16:437-45.

23. Suhonen R, Välimäki M, Leino-Kilpi H. Individualized care, quality of life and satisfaction with nursing care. J Adv Nurs 2005;50:283-92.

24. Johansson H, Eklund M. Patients' opinion on what constitutes good psychiatric care. Scand J Caring Sci 2003;17:339-46.

25. Richardson S, Casey M, Hider P. Following the patient journey: older persons' experiences of emergency departments and discharge. Accid Emerg Nurs 2007;15:134-40.

26. Stoker S, Sayers A. Doesthe essence of care live up to patient expectations? Practice Development in Health Care 2002;1:67-76.

27. Schofield I, Tolson D, Arthur D, et al. An exploration of the caring attributes and perceptions of work place change among gerontological nursing staff in England, Scotland and China (Hong Kong). Int J Nurs Stud 2005;42:197-209.

28. Merkouris A, Andreadou A, Athini E, et al. Assessment of patient satisfaction in public hospitals in cyprus: a descriptive study. Health Science Journal 2013;7:28-40.

29. Mogadasiyan S, Abdolahzadeh F, Rahmani A, et al. Satisfaction with nursing care and related factors in hospitalized cancer patients in shahid ghazi hospital in tabriz. Journal of Urmia Nursing \& Midwifery Faculty 2013;11.

30. Johannessen G, Eikeland A, Stubberud DG, et al. A descriptive study of patient satisfaction and the structural factors of Norwegian intensive care nursing. Intensive Crit Care Nurs 2011;27:281-9.

31. Han $\mathrm{CH}$, Connolly PM, Canham D. Measuring patient satisfaction as an outcome of nursing care at a teaching hospital of southern Taiwan. J Nurs Care Qual 2003;18:143-50.

32. Ofovwe CE, Ofili AN. Indices of patient satisfaction in an African population. Public Health 2005;119:582-6.

33. Feysia B, Herbst $\mathrm{C}$, Lemma W. The health workforce in ethiopia: Addressing the remaining challenges. World Bank Publications 2012.

34. Kinfu Y, Dal Poz MR, Mercer $\mathrm{H}$, et al. The health worker shortage in Africa: are enough physicians and nurses being trained? Bull World Health Organ 2009;87:225-30.

35. WHO. Ethiopia: Health workforce. 2018 http://www.aho.afro.who.int/ profiles_information/index.php/Ethiopia:Health_workforce_-_The_ Health_System (accessed 23 Feb 2018).

36. Tilahun YG, Nasrabadi A, Alemayehu M, et al. The journey of ethiopian nursing education: a glimpse of past, present and future. International Journal of Current Research 2016;8.

37. Chaaya M, Rahal B, Morou G, et al. Implementing patient-centered care in Lebanon. J Nurs Adm 2003;33:437-40.

38. Avis M, Bond M, Arthur A. Satisfying solutions? A review of some unresolved issues in the measurement of patient satisfaction. $J A d v$ Nurs 1995;22:316-22.
39. Lin CC. Patient satisfaction with nursing care as an outcome variable: dilemmas for nursing evaluation researchers. J Prof Nurs 1996;12:207-16.

40. Aynalem Tesfay F, Dejenie Habtewold T. Assessment of prevalence and determinants of occupational exposure to HIV Infection among healthcare workers in selected health institutions in Debre Berhan Town, North Shoa Zone, Amhara Region, Ethiopia, 2014. AIDS Res Treat 2014;2014:1-11.

41. The Ethiopian Herald. Ethiopia: Hospital reform improving health care service delivery. http://allafrica.com/stories/201707100519.html 2018 (accessed 21 Feb 2018).

42. Kolola T, Gezahegn T. A twenty-four-hour observational study of hand hygiene compliance among health-care workers in Debre Berhan referral hospital, Ethiopia. Antimicrob Resist Infect Control 2017;6:109.

43. Thomas LH, McColl E, Priest J, et al. Newcastle satisfaction with nursing scales: an instrument for quality assessments of nursing care. Qual Health Care 1996;5:67-72.

44. Piredda M, Vellone E, Piras G, et al. Psychometric evaluation of the newcastle satisfaction with nursing scales. J Nurs Care Qual 2015;30:84-92.

45. lacobucci D, Posavac SS, Kardes FR, et al. Toward a more nuanced understanding of the statistical properties of a median split. Journal of Consumer Psychology 2015;25:652-65.

46. von Elm E, Altman DG, Egger M, et al. The Strengthening the Reporting of Observational Studies in Epidemiology (STROBE) statement: guidelines for reporting observational studies. Prev Med 2007;45:247-51.

47. Alasad JA, Ahmad MM. Patients' satisfaction with nursing care in Jordan. Int J Health Care Qual Assur 2003;16:279-85.

48. Ebrahim SM, Issa SS. Satisfaction with nursing care among patients attending oncology center in Basra city, Iraq. Journal of Environmental Science and Engineering 2015:241-8.

49. Ahmed T, Assefa N, Demisie A, et al. Levels of adult patients' satisfaction with nursing care in selected public hospitals in ethiopia. Int $J$ Health Sci 2014;8:375-83.

50. Woldeyohanes TR, Woldehaimanot TE, Kerie MW, et al. Perceived patient satisfaction with in-patient services at Jimma University Specialized Hospital, Southwest Ethiopia. BMC Res Notes 2015;8:285.

51. Dzomeku V, Ba-Etilayoo A, Perekuu T, et al. In patient satisfaction with nursing care: a case study at kwame nkrumah university of science and technology hospital. International Journal of Research in Medical and Health Sciences 2013;2:19-24.

52. Findik UY, Unsar S, Sut N. Patient satisfaction with nursing care and its relationship with patient characteristics. Nurs Health Sci 2010;12:162-9.

53. Baron-Epel O, Dushenat M, Friedman N. Evaluation of the consumer model: relationship between patients' expectations, perceptions and satisfaction with care. Int J Qual Health Care 2001;13:317-23. 